\title{
Doctrinas, normas y figuras jurídicas para el despojo del patrimonio nacional
}

Legal doctrines, rules, and schemes for the pillage of the Nation's patrimony

Jorge Francisco Cholvis del Instituo A Arture Enrique Snip Docente de la Univerida Sampay. de Lanús

Fecha de recepción:

19.4.17

Fecha de aceptación

\section{Resumen}

Los decretos 29 y 231 dictados en meses recientes por el Poder Ejecutivo Nacional disponen la prórroga de jurisdicción y la renuncia a la defensa de inmunidad soberana en beneficio de tribunales de Nueva York, Londres y la Confederación Suiza, en futuras emisiones de deuda externa, y afecta los recursos del Estado nacional como garantía del cumplimiento de los convenios que se celebren a esos efectos. El artículo elabora una visión crítica de esas normas y destaca el carácter nocivo de los mismos, en una perspectiva de desarrollo, derechos humanos y justicia social.

Palabras clave: prórroga de jurisdicción - endeudamiento externo - recursos naturales - fuga de capitales - Argentina.

Abstract

Executive decrees 29 and 231 issued in recent months set the extension of jurisdiction of Argentina's state towards courts in New York City, London and the Helvetic Confederation, together with the abdication of the right to appeal at the principle of sovereign immunity, in future emissions of foreign debt bond, affecting state-owned resources as guaranty of honoring such deals. A critical appraisal of both decrees is conducted in this article, as- 
sessing the negative impact of both from the standpoint of economic development, human rights and social justice.

Key-words: extension of jurisdiction - foreign indebtedness natural resources - capital runaway - Argentina.

\section{Diferentes concepciones sobre convenios de financiamiento}

Con la asunción del gobierno del presidente Mauricio Macri, se retomó el antiguo modelo económico basado en el endeudamiento externo y la valorización financiera del capital: dólares que se pasan a pesos en una revivida bicicleta financiera para obtener enormes ganancias aprovechando las altas tasas de interés, que después se fugan a empresas off-shore, a guaridas financieras, como son las creadas en los denominados "parásos fiscales", donde amparados por la figura jurídica de sociedades que no ejercen actividad industrial ni empresarial, conforman instrumentos de lo que se conoce en el mundo contemporáneo como la versión salvaje del capitalismo financiero. El endeudamiento público vuelve a ser en Argentina una cuestión gravísima que condicionará todas las políticas económicas. Es el contraste de la proclamada "pobreza cero" con la dura realidad de la economía. Los documentos que trataremos conforman un aspecto de la trama jurídica de sometimiento y son instrumentos para el saqueo de nuestros recursos naturales.

Por los Decretos No 29, del 11 de enero y el № 231 del 5 de abril, ambos de 2017, se autoriza al Ministerio de Finanzas a emitir deuda y se lo faculta a incluir cláusulas que establezcan la prórroga de jurisdicción a favor de tribunales extranjeros (radicados en las ciudades de Nueva York, Estados Unidos de América, y Londres, del Reino Unido de Gran Bretaña e Irlanda del Norte, indica el decreto $\mathrm{N}^{\circ} 29$, y los que tienen sede en la Confederación Suiza según el decreto $N^{\circ}$ 231) y la renuncia a oponer "la defensa de inmunidad soberana”, respecto a reclamos que se pudieran producir en la jurisdicción que se prorrogue, con relación a los acuerdos que se suscriban y a las emisiones de deuda pública que se realicen. El 25 de enero pasado el Ministerio de Finanzas dictó la Resolución $\mathrm{N}^{\circ} 5$, que efectiviza la renuncia de principios soberanos, y políticas que van a condicionar al país.

Históricamente Argentina aplicó el principio de inmunidad soberana absoluta: el Estado sólo podía ser juzgado en los tribunales propios de su organización jurisdiccional doméstica. Finalizada la Segunda Guerra Mundial desde los estados desarrollados se fue imponiendo gradualmente la doctrina de la inmunidad relativa, para así reemplazar el principio de la inmunidad absoluta, y asegurar su penetración económica en países de- pendientes. Para ello distinguen entre actos "iure imperii" -considerados como actos soberanos por lo cual gozan de inmunidad- y actos "iure gestionis" -considerados como actos privados-, carentes de ese derecho soberano. Ese criterio lo aplican especialmente en relación a los "convenios de financiamiento" con los cuales instrumentan el endeudamiento con el que atan a los países en desarrollo. El desmantelamiento del patrimonio y de las capacidades estatales de decisión soberana se apoya en un entramado jurídico internacional orientado a recortar adicionalmente la capacidad de decisión soberana de los estados dominados, constituyendo un intervencionismo neocolonial. La prórroga de jurisdicción a foros judiciales extranjeros y a tribunales internacionales se acentúa en los tiempos de la globalización financiera como un requerimiento fundamental del capital especulativo. De esa forma privilegian los intereses del capital mundialmente concentrado en pocas personas, por sobre las necesidades básicas insatisfechas de los pueblos que cargan con el peso del endeudamiento.

Arturo E. Sampay sostuvo que mediante la prórroga de jurisdicción los países dominantes imponen una administración de justicia "ad hoc" a los países dominados, y de tal modo, ante las controversias de intereses en las que son parte la utilizan como instrumentos para apropiarse en gran escala de los recursos naturales de esos países, pues los conflictos que se suscitan "deben ser dilucidados ante los tribunales del exterior que ellos determinan; sin eufemismo hablando: ante sus jueces. Como es de observar, se trata de una fibra más de las que componen la coyunda con que atan a su yugo a los países dependientes".

En tanto que en estos casos está en juego el orden público constitucional dado que no se trata de meros problemas de naturaleza comercial, sino que tienen naturaleza pública y comprometen facultades "ius imperium" del Estado, en base a principios sostenidos por Bernardo de Irigoyen, Carlos Calvo, Luis M. Drago, Carlos Saavedra Lamas, José Nicolás Matienzo, Arturo E. Sampay, entre otros notables juristas de nuestro país que dejaron hitos imborrables en la defensa de nuestro pueblo y que forjaron lo que se conoció como "Doctrina Argentina", sostenemos que las operaciones de crédito público son actos "iuri imperii", íntimamente vinculados al principio de soberanía y, por lo tanto, encuadrados en el concepto de la inmunidad de jurisdicción, la que por ser de orden público debe ser irrenunciable.

En las operaciones de crédito público sostener la soberanía jurisdiccional y la inmunidad de ejecución conforman principios rectores del ordenamiento jurídico nacional, pues afectan el orden público e interés institucional de la Nación Argentina que se encuentra amparado por los arts. 27, 31, 75 incs. 4, 8, 19, 22, 23 y 24, y 116 de la Constitución Nacional, el que fue receptado en casos rectores de la Corte Suprema de Justicia de la Nación (en adelante CSJN), ya sea antes de la reforma constitucional de 1994 tales como "Compte c/ Ibarra" de 1936; "Empresa de Navegación y Astillero Bussio" de 1967; y en los fallos que emitió después de ser sancionado el texto constitucional 
vigente, en los casos "Brunicardi, Adriano c/ Estado Nacional" -en el cual la CSJN entendió a la refinanciación de deuda como un empréstito público erigido en base al poder soberano estatal, es decir, como acto "iure imperii-; o en el caso "Clarence Corporation" del año 2014, al sostener que no pueden ser pasibles de ejecución las sentencias que afecten el orden público constitucional, por ser incompatibles con el bloque federal formado por dichos artículos de la Constitución Nacional. Lo contrario es desconocer el sistema jerárquico de prelación normativa. Por ello, cabe tener presente también, que el 3 de febrero de 2012, la Corte Internacional de Justicia en "Alemania vs. Italia (Grecia interviniente)", sentó que las operaciones de crédito público son actos iure imperii.

Es necesario insistir que la prórroga de jurisdicción no conlleva implícitamente a una pérdida de las defensas y excepciones que pueda plantear el Estado al momento que le exijan el cumplimiento forzado de una sentencia o laudo condenatorio. Pues es en dicha instancia que ingresa a tallar la inmunidad de ejecución. Una sentencia que confronte con dicho principio ningún efecto puede causar. No deben ser consideradas título hábil para erigir el andamiaje del cobro compulsivo por medio de la ejecución forzada. Las normas de procedimientos del país prevén especialmente que deben concurrir una serie de elementos para la ejecución de sentencias extranjeras, como que no afecte los principios de orden público del derecho argentino, pues el mismo no debe ser materia transable. Tal doctrina fue sostenida por la CSJN en el mencionado pronunciamiento del "caso Clarence", que precedido de un dictamen de la Procuradora General de la Nación, recoge la mejor doctrina y jurisprudencia en materia de resguardo del orden público constitucional de la Nación Argentina.

Los decretos 29 y 231 de 2017 posibilitan oponer la defensa de inmunidad soberana con relación a los bienes que se detallan en los incisos a) a j) de su art. $1^{\circ}$, y pareciera que con ello se ampara plenamente al patrimonio nacional. Sin embargo no es así. Los bienes que comprenden dichos incisos son los relativos a las reservas del BCRA; o bienes que pertenezcan al dominio público localizado en el territorio de la República Argentina, incluyendo los comprendidos por los Artículos 234 y 235 del Código Civil y Comercial de la Nación; bienes localizados dentro o fuera del territorio argentino que presten un servicio público esencial; o los utilizados por una misión diplomática, gubernamental o consular de la República Argentina;impuestos y/o regalías adeudadas a la Argentina; los bienes de carácter militar o bajo el control de autoridad militar o agencia de defensa de la República Argentina; los que forman parte de la herencia cultural de la Argentina; los bienes protegidos por cualquier ley de inmunidad soberana que resulte aplicable. Los bienes individualizados por el artículo 234 del Código Civil y Comercial de la Nación son los que se encuentran fuera del comercio, y los del artículo 235 son los pertenecientes precisamente al dominio público, como ser entre otros el mar territorial, aguas interiores, bahías, puertos; ríos, estuarios, arroyos, lagos y lagunas navegables; islas que se formen en el mar territorial; el espacio aéreo supra yacente al territorio y aguas juris- diccionales; calles, plazas caminos, canales; etc. Dichos bienes, estuvieron considerados en forma similar en anteriores normas relativas a convenios de financiamiento externo.

Sin embargo, es necesario resaltar que ambos decretos dejan al margen del principio de la inmunidad soberana de jurisdicción y ejecución a los bienes del artículo 236 del Código Civil y Comercial de la Nación, que son los del dominio privado del Estado nacional, provincial o municipal. Dicho artículo establece expresamente que

pertenecen al Estado nacional, provincial o municipal, sin periuicio de lo dispuesto en leyes especiales: (...) b) las minas de oro, plata, cobre, piedras preciosas, sustancias fósiles y toda otra de interés similar, según lo normado por el Código de Minería; (...) e) los bienes adquiridos por el Estado nacional, provincial o municipal por cualquier título".

Es decir, quedan fuera de la protección de la inmunidad soberana por ejemplo, los recursos hidrocarburíferos, el litio y otros recursos minerales estratégicos de los cuales el país contiene importantes yacimientos; también las empresas del Estado.

Otra etapa determinante de la "trama" y que es indispensable conocer, es la Resolución $N^{\circ} 5(25 / 01 / 2017)$ del Ministerio de Finanzas que con base en el decreto 29, dispone la emisión de nuevos instrumentos de deuda pública, cuyas condiciones detalla en el Anexo I, de la misma por hasta la suma de u $\$ \mathbf{s} 7.000$ millones (art. $1^{\circ}$ ); designa a BBVA Securities Inc., Citi Group Global Markets Inc., Deutsche Bank Securities Inc., HSBC Securities (USA) Inc., J. P. Morgan Securities LLC y Santander Investement Securities Inc., como colocadores conjuntos de los instrumentos públicos; aprueba los modelos de la documentación inherente a la operación de financiamiento, "cuyos ejemplares en idioma inglés y su traducción al español forman parte integrante de la presente medida", con el siguiente detalle:Anexo II "Memorándum Preliminar de la Oferta" "Preliminary Offering Memorandum)", el cual será sustancialmente igual al "Memorándum Final de la Oferta" "“Final Offering Memorandum)"; Anexo III, "Acuerdo de Compra" ("Purchase Agreement)"; Anexo IV, "Acuerdo de Registración" ("Registration Rights Agreement)", designa a The Bank of New York Mellon como Agente Fiduciario y Agente de Pago y Agente de Listado en el Gran Ducado de Luxemburgo, y por los AnexosV yVI aprueba el esquema de Gastos y Honorarios por su intervención; y en el Anexo VII determina "topes" para "los gastos de registración, impresión, distribución de prospectos, traducción y otros gastos asociados habituales que resulten necesarios" (sic).

En estos Anexos encontramos no sólo precisiones sobre la mecánica de la operación sino que en ellos también se destaca información económica y financiera seleccionada sobre la República, con una concepción acorde a las políticas de la ortodoxia 
económica propuesta por los organismos financieros internacionales y conglomerados financieros, las que son seguidas desde las altas esferas del gobierno. Ciertamente, dichos "Memorandos". "Prospectos" y "Acuerdos", traen a la memoria la muy similar y no lejana trama elaborada desde el F.M.I. y otros organismos internacionales de crédito, actualmente impulsada desde el conglomerado financiero internacional en esta etapa de "capitalismo salvaje". Por ejemplo, en el Anexo II ("Prospecto Preliminar) el gobierno nacional anuncia al conglomerado financiero internacional y asume compromisos sobre las políticas socioeconómicas; indica cifras de producción (primaria y secundaria); política monetaria; "régimen de sinceramiento fiscal" (es decir blanqueo); deuda del sector público, sistema monetario. Señala también que "a la fecha de este prospecto el gobierno de Macri ha eliminado gran parte de las restricciones cambiarias"; que ha de reducir subsidios a la energía, gas y transporte, y que "los precios promedio de la electricidad y el gas ya han aumentado y podrían aumentar más". Que el Banco Central de la República Argentina "ha incrementado sus esfuerzos para reducir el desequilibrio monetario y aumentado las tasas de interés en pesos para compensar la presión inflacionaria", y controlar el gasto público, entre otros muchos otros condicionantes que sería largo enumerar. También anuncia que "el proyecto de ley (Programa de Reparación Histórica para Jubilados y Pensionados) establece que los activos del Fondo de Garantía de Sustentabilidad (FGS), incluidas las acciones correspondientes puede ser vendido para financiar el programa". Además, advierte que el contrato de Fideicomiso que rige los bonos incluye entre otras cosas, compromisos que limitan la capacidad de la República en varios aspectos, tal el de constituir gravámenes sobre sus activos.

El Anexo I cuando se refiere a la Ley y Jurisdicción aplicable, dice que "se regirán por la ley del Estado de Nueva York, Estados Unidos de América, y de acuerdo a los términos y condiciones del Convenio de Fideicomiso ("Trust Indenture)", y con relación a la Jurisdicción precisa que sujeto a ciertas excepciones "la República Argentina se someterá irrevocablemente a la jurisdicción exclusiva de cualquier tribunal estadual del Estado de Nueva York o federal en el Distrito de Manhattan, Ciudad de Nueva York, Estados Unidos de América, y de los tribunales de la República Argentina (...) en cualquier juicio, acción o proceso legal contra la República Argentina o sus bienes, activos o ingresos que surja de o relacionado con los Bonos o el incumplimiento o supuesto incumplimiento de Argentina de cualquier obligación bajo los Bonos (un "Proceso Legal Relacionado"). La República Argentina renuncia irrevocable e incondicionalmente, en la máxima medida permitida por la ley, a cualquier defensa que pueda o pudiera interponer en cualquier Proceso Legal Relacionado iniciado ante un Tribunal Específico ya sea por jurisdicción, residencia o domicilio o porque dicho Proceso Legal Relacionado fue iniciado en un foro no conveniente". A continuación reafirma en un extenso párrafo que, "en la medida en que la República Argentina o cualquiera de sus ingresos activos o bienes tengan derecho, en cualquier jurisdicción en que se encuentre cualquier Tribunal Específico, en el que cualquier Proceso Legal Relacionado pueda en cualquier momento iniciarse contra ésta o cualquier de sus ingresos, activos, o bienes, o en cualquier jurisdicción en que se encuentre el Tribunal Específico en el que algún juicio, acción, o proceso legal pueda en cualquier momento iniciarse con el fin de ejecutar cualquier sentencia emitida en cualquier Proceso Legal Relacionado (una "Sentencia Relacionada") contra cualquier inmunidad de juicio, de jurisdicción de dicho Tribunal Específico, de compensación, de embargo previo a sentencia, de embargo en ejecución de sentencia, de ejecución de una sentencia o de cualquier otro proceso o recurso legal o judicial, y en la medida en que dicha jurisdicción se haya atribuido dicha inmunidad, la República Argentina renuncia irrevocablemente a dicha inmunidad, en la máxima medida permitida por las leyes de dicha jurisdicción, incluso la Foreing Sovereign Inmmunities Act. de los Estados Unidos de América (la FSIA)" (sic). Se dan un baño de patriotismo y aclaran que dicha renuncia no se extenderá a los bienes señalados en los incs., a) y j) del art. $1^{\circ}$ del Decreto 29/17, pero como vimos anteriormente, la inmunidad en cuestión no alcanza a los bienes que individualiza el artículo 236 del Código Unificado Civil y Comercial.

El Anexo II anuncia que el 9 de noviembre de 2016, el FMI concluyó la misión de consulta del Artículo IV con Argentina y basándose en lo que establece el Convenio Constitutivo del FMI, deja constancia que "mantendrá reuniones bilaterales con los países miembros, generalmente una vez al año"; y que "el personal del FMI realiza una visita al país, reúne información económica y financiera, y analiza las políticas y los sucesos económicos del país con los funcionarios", para que el personal del FMI elabore un informe para el Directorio Ejecutivo. A continuación dicho Anexo dispone que "los fondos netos de los Bonos de la presente oferta se utilizarán para objetivos generales del gobierno, incluyendo la refinanciación", y que "los Bonos serán obligaciones directas, generales, incondicionales y no subordinadas de la República respaldados por el pleno reconocimiento y crédito de la República”. Cuando trata de la Exigibilidad de Responsabilidad Civil, luego de señalar lo evidente que "la República es un Estado soberano", reitera que "con el mayor alcance permitido por la legislación aplicable, la República se someterá irrevocablemente a la jurisdicción exclusiva de cualquier tribunal del Estado de Nueva York o cualquier tribunal federal de los Estados Unidos con asiento en el Distrito de Manhattan, Ciudad de Nueva York, y los tribunales de la República (...) La República renuncia de forma irrevocable e incondicional, con el mayor alcance permitido por la ley, a cualquier objeción que pudiera tener contra Procedimientos Relacionados iniciados en un Tribunal Especificado, ya sea por razón de competencia territorial, residencia o domicilio o en razón de que dichos Procedimientos Relacionados se hubieran iniciado en un foro inconveniente", y reafirma que "la República renuncia en forma irrevocable a dicha inmunidad con el mayor alcance permitido por las leyes de dicha jurisdicción, con inclusión de la Ley de Inmunidad de Soberanía Extranjera de Estados Unidos de 1976 (United States Foreing Sovereign Inmmunities Act of 1976, ("FSIA"). También remarca que "en base a la legislación existente, los tribunales de la Argentina ejecutarán dicha sentencia de conformidad 
con los términos y condiciones de los tratados celebrados entre la Argentina y el país en el que se dictó la sentencia". También aclara que "este prospecto contiene manifestaciones con proyección de futuro", que "se basan en los actuales planes, estimaciones y proyectos de la República"; y que "es posible que la recaudación impositiva y los resultados fiscales futuros de la República no sean suficientes para pagar el servicio de la deuda y, por lo tanto, la República deba recurrir, en parte a financiamiento adicional de mercados de capitales nacionales e internacionales a fin de cumplir con futuras obligaciones del servicio de la deuda".

El Anexo III al tratar el tema de la Inmunidad, además de repetir términos de Anexos anteriores, como para que no quede duda alguna señala sin amedrentarse que "la renuncia a la inmunidad por la República incluida en la cláusula 15 del presente, cláusula 9.7 del Convenio de Fideidomiso y la cláusula 6 (j) del Convenio de Derechos de Registro, y la indemnización y las disposiciones de contribución incluidas en la cláusula 7 del presente no entran en conflicto con la ley o la política de orden público de la Argentina". Cuando trata la Forma Legal, sostienen que "los documentos de la Operación guardan la debida forma legal de conformidad con la legislación de la República para la ejecución de los mismos".Y al tratar los Requisitos legales expresa que "no es necesario para garantizar la legalidad, validez, exigibilidad o admisibilidad en prueba en la Argentina de los Documentos de la Operación, que los Documentos de la Operación o cualquier otro documento o instrumento en virtud del presente o de los mismos sea registrado, inscripto o presentado ante alguna autoridad judicial u otra autoridad en la Argentina o que sea protocolizado". Este Anexo, asumiendo incumbencias que no le corresponde y vedadas por la Constitución al Poder Ejecutivo, al referirse a la Ejecución de Sentencias extranjeras promete que las mismas serían declaradas "exigible contra la República por cualquier tribunal de la Argentina, sin reconsideración o nuevo examen de los méritos del caso", con sujeción a las condiciones que detalla y entre los cuales figura que "la sentencia no debe violar los principios de orden público de la ley argentina" (sic). Pero después en el tema "Indemnización y Contribución", con el mayor grado de cipayismo que se puede alcanzar, dice que "las disposiciones de indemnización y contribución establecidas en la cláusula 7 del presente no violan la ley ni el orden público de la República Argentina”.

No se puede dejar de remarcar los supuestos de incumplimiento con relación a la República que determinan los Anexos para la aceleración del pago del capital de los Bonos más los intereses devengados: además de mencionar la falta de pago por 30 días; incumplimiento de obligaciones y de cualquier serie de Bonos o el Contrato de Fideicomiso; incorpora que la República no podrá efectuar una declaración de sobre moratoria; y también veda a la República impugnar la validez de cualquier serie de Bonos. Por si fuera poco agraviante para el país lo precedente, el Anexo III, "Convenio de Compra", en su punto 3, Declaraciones y Garantías, agrega otra grave claudicación al instituir que la República estará sometida a las autodenominadas "calificadoras de riesgo", que fueron utilizadas y son instrumento del gran capital financiero "globalizado", pues allí en bb) Calificaciones, se "declara y garantiza a cada comprador" que "la República no ha recibido notificación alguna de parte de Moody's Investors Service, Inc. ("Moody's") o de Standard \& Poor's Ratings Service ("Standard \& Poor's"), de que alguna de ellas tuviera la intención de disminuir la calificación otorgada a los títulos de deuda de la República a cualquier categoría de calificación igual o inferior a B3 o B, o que estuviera contemplado disminuir la calificación otorgada a los títulos de deuda de la República a cualquier categoría de calificación igual o inferior a B3 o B". En el punto 5. Titulado "Condiciones de las obligaciones de los compradores iniciales", establece que las mismas están sujetas al cumplimiento por la República de sus pactos y obligaciones, y a las condiciones adicionales por las que se le prohíbe la disminución en la calificación de riesgo. El punto c) Calificación, concluye:"La República realizará sus mejores esfuerzos para que los Títulos sean calificados por Moody's y Standard and Poor's a la brevedad posible, luego de la formalización y otorgamiento de este Convenio" (sic).

Otra actitud grave de sometimiento es cuando se refiere a Distorsiones del Mercado y reitera en el inc., t) que "las autoridades de la Argentina, las autoridades federales de los Estados Unidos o del Estado de Nueva York no deben haber declarado una moratoria bancaria.Y por si fuera poco lo precedente poco después en el punto 15, Disposiciones varias, e) in fine, dice que "la República conviene que el artículo 765 del Código Civil y Comercial de la Nación Argentina no será de aplicación al presente Convenio ni a los documentos de la Operación". Por ello debemos recordar que esta disposición perdida en el Anexo margina al citado artículo que expresamente señala que "si por el acto por el que se ha constituido la obligación, se estipuló dar moneda que no sea de curso legal en la República, la obligación debe considerarse como de dar cantidades de cosas y el deudor puede liberarse dando el equivalente en moneda de curso legal". Para el gobierno nacional en su claudicante actitud, la Argentina no tiene moneda propia, y siguiendo las políticas impuestas se somete a que sólo existen "dólares".

Para argumentar la validez de los Bonos expresa el Prospecto que el Procurador General del Tesoro de la República Argentina y Cleary Gottlieb Steen \& Hamilton LLP, asesores legales estadounidenses especiales de la República, emitirán una opinión para la República sobre la validez de los Bonos. Sherman \& Sterling LLP, asesores legales estadounidenses de los Compradores iniciales enunciados en este prospecto, y Bruchou, Fernández Madero \& Lombardi, asesores legales sobre argentina de los Compradores iniciales enunciados en este prospecto, emitirán una opinión para estos sobre la validez de los Bonos. Respecto de las cuestiones de legislación Argentina Cleary Gottlieb \& Hamilton LLP se basarán en la opinión del Procurador General del Tesoro de la República Argentina; y Sherman \& Sterling LLP se basarán en la opinión de Bruchou, Fernández Madero \& Lombardi.

El Anexo IV “Acuerdo sobre Derechos de Registro. Derecho Aplicable”, también reitera 
conceptos incluidos en los anexos anteriores; y los Anexos V,VI y VII, se refieren -como señalamos antes- a temas de Honorarios y cargos, Información confidencial contenida en el Esquema de Honorarios, Cargos y Límites de Gastos, que no obstante generar otras leoninas obligaciones para el país, su análisis nos aleja del tema de fondo tratado en el presente.

Como vimos fue el 5 de abril de 2017, que se realizó el último acto hasta el momento de la senda que conduce hacia el descomunal endeudamiento externo que se está colocando al país. Ese día el Poder Ejecutivo Nacional emitió el decreto $\mathrm{N}^{\circ} 231$, donde se estableció que en el marco de la estrategia financiera integral y del programa financiero para el ejercicio 2017, "se continuarán realizando colocaciones en los mercados financieros internacionales, incluyendo en este caso los de la Confederación Suiza”, y para ello faculta al Ministerio de Finanzas por hasta un monto que no supere la suma de V. N. Ch F 3.000.000, y "a incluir cláusulas que establezcan la prórroga de jurisdicción a favor de los tribunales arbitrales y judiciales en sede de la Confederación Suiza, y que dispongan la renuncia a oponer la defensa de inmunidad soberana", respecto a los reclamos y con las excepciones de los bienes que detalla- El diseño es similar al del decreto $N^{\circ} 29$ que hemos descripto pero con la diferencia que éste autorizó un endeudamiento por u\$s 20.000.000. Cabe señalar que hasta la fecha no se publicó la resolución que el Ministerio de Finanzas debe dictar referente al decreto 231.

A modo de conclusión podemos señalar que estamos ante uno de los mecanismos de despojo/saqueo, promovido e instrumentado desde los países centrales y sus corporaciones financieras, en pugna con el desarrollo autónomo de los países periféricos/ dependientes. La deuda en moneda extranjera que se está contrayendo por el país, es insostenible, y embarga a generaciones futuras de argentinos. Es el presupuesto y vía principal utilizada para financiar la fuga de divisas. Un decreto, una ley, toda norma jurídica siempre se nutren de una concepción política y refleja intereses, aunque estos no se manifiesten expresamente. El pueblo argentino está siendo víctima de un verdadero saqueo de dimensiones incalculables. Las políticas neoliberales llevaron a la crisis del 2001/2, y ahora nos conducen otra situación de desastre similar.

Resulta imposible desconocer por ello que el endeudamiento ocurrido desde enero de 2016 a la actualidad socava los derechos humanos del pueblo argentino. Sostenemos que los derechos humanos proporcionaran un marco claro y universalmente reconocido en el que pueda basarse la formulación de una definición jurídica y de políticas nacionales a adoptarse por el país, en relación al problema.

Dar vigencia plena a los derechos humanos básicos es la cuestión principal del derecho contemporáneo. Los antecedentes normativos que surgen del nuevo derecho internacional de los Derechos Humanos, permiten sostener que la inmunidad de jurisdicción de un
Estado es la directriz general y cuenta con la fuerza de una norma de derecho consuetudinario imperativo -ius cogens- ajustado al sistema del Derecho Internacional Público.

El Pacto Internacional de Derechos Económicos, Sociales y Culturales, que según lo dispuesto por el art. 75 inc. 22 de la Constitución ha sido incorporado al ordenamiento jurídico argentino y "tiene jerarquía constitucional”, en su artículo $1^{\circ}$ establece que los pueblos tienen el derecho a la libre determinación", y que en virtud de este derecho establecen libremente su condición política y proveen asimismo a su desarrollo económico, social y cultural (1.1); y para el logro de sus fines, "todos los pueblos pueden disponer libremente de sus riquezas y recursos naturales", y que "en ningún caso podría privarse a un pueblo de sus propios medios de subsistencia" (1.2). También el Pacto Internacional de Derechos Civiles y Políticos incorpora en su artículo $1^{\circ}$ similares principios.

Los decretos 29 y 231 de 2017 y las normas dictadas en su aplicación afectan gravemente la soberanía nacional por las renuncias y condicionamientos que contienen; habilitan a los acreedores a litigar contra el país en jurisdicción y con legislación externa poniendo en peligro los recursos naturales. Por lo que vimos antes, es someterse a la justicia "ad hoc" de otros países indicados en los convenios de financiamiento, que es donde se dirimirá el conflicto si la argentina, impugna la validez de la deuda, plantea una moratoria o ingresa en default. En Nueva York y Londres se rematarán en tal caso los recursos naturales por los compromisos financieros asumidos por el gobierno de Macri. Y ello coloca en una situación totalmente vulnerable al Estado respecto del control, protección y utilización de nuestros recursos y riquezas naturales.

Por tanto, es imprescindible tener presente que los bienes que enuncia el arts. 236 del Código Civil y Comercial, y que forman parte del patrimonio nacional, al quedar desamparados de protección en cuanto a la inmunidad soberana de jurisdicción y ejecución, serán pasibles del saqueo al quedar colocados en primera línea como garantía del pago del endeudamiento. Sin duda, ello afecta al patrimonio nacional y es claro que la Argentina por esta vía sufre una limitación sustancial en el ejercicio de su soberanía. La consecuencia será la violación de los derechos humanos básicos. Será indispensable entonces, abrir el debate sobre la gravedad del problema,y de tal forma, con la participación protagónica del pueblo lograr impulsar y adoptar políticas precisas para que ello no ocurra. 